Article

\title{
Building a Disaster-Resilient Community in Taiwan: A Social Capital Analysis of the Meizhou Experience
}

\author{
Alan Hao Yang ${ }^{1,2, *}$ and Judy Shu-Hsien $\mathrm{Wu}^{1}$ \\ ${ }^{1}$ Graduate Institute of East Asian Studies, National Chengchi University, 11605 Taipei City, Taiwan; \\ E-Mails: alanhao@nccu.edu.tw (A.H.Y.), 106260501@nccu.edu.tw (J.S.-H.W.) \\ 2 Institute of International Relations, National Chengchi University, 11605 Taipei City, Taiwan \\ * Corresponding author
}

Submitted: 5 April 2020 | Accepted: 30 June 2020 | Published: 10 December 2020

\begin{abstract}
Resilience has always been key to successful disaster governance throughout the world. Local communities can play an important role in promoting disaster preparedness and executing front-line relief to strengthen the effectiveness and efficiency of both local and national disaster governance. This article addresses a unique case of how a flood-prone, rural, and ageing community in Yilan County, Taiwan, successfully mobilized its citizens for disaster preparedness. Through the lens of social capital analysis, this article unpacks how Bonding Social Capital, Bridging Social Capital, and Linking Social Capital work, by tracing the process through which awareness of disaster resilience was developed and practised in the Meizhou Community. Since 2012, Meizhou has been recognized as a model of disaster preparedness and relief in Taiwan, and in 2019 this recognition was extended to the wider Indo-Pacific region. We begin the discussion of this article by contextualizing social capital as a theoretical departure to the empirical analysis of the Meizhou experience. This is followed by an exploration of how Bonding Social Capital was able to consolidate the community, and how Bridging Social Capital can facilitate the collaboration among functional groups in and beyond the Meizhou locality, and to what extent Linking Social Capital can implement Meizhou's experience on a national and even international scale. This article is based on a qualitative assessment of long-term fieldwork, interviews, and participatory observation conducted by the authors in the Meizhou community.
\end{abstract}

\section{Keywords}

community-based governance; disaster preparedness; disaster resilience; Meizhou; social capital; Taiwan

\section{Issue}

This article is part of the issue "The Politics of Disaster Governance" edited by Dorothea Hilhorst (Erasmus University Rotterdam, The Netherlands), Kees Boersma (Vrije Universiteit Amsterdam, The Netherlands) and Emmanuel Raju (University of Copenhagen, Denmark).

(C) 2020 by the authors; licensee Cogitatio (Lisbon, Portugal). This article is licensed under a Creative Commons Attribution 4.0 International License (CC BY).

\section{Introduction}

Given the ongoing climate emergency, extreme weather conditions such as heavy rainfall, typhoons, landslides, and other related hazards have posed serious threats to people's safety and welfare across the world. Taiwan is located on the edge of the Pacific Ocean and subject to Western Pacific typhoons. It has suffered from torrential rainfall, floods, landslides, and other related disasters throughout its history. In recent years, although most countries have devoted resources and devised policies as well as relief plans to mitigate the effects of natural disasters by carrying out disaster relief, major natural disasters still have a serious impact on people's livelihoods. To reduce such losses, disaster management has gradually shifted toward a resilience-oriented model. This shift toward resilience has two features: First, although the government still plays a key role in disaster governance, 
successful disaster management must involve diverse partnerships incorporating increasing numbers of stakeholders or actors into the governance network to enable it to provide public services more efficiently and effectively. This also means that it is necessary to form innovative cross-sectoral partnerships, connecting, for example, local communities and other stakeholders or organizations to implement coordination or collaboration projects (Chen \& Ku, 2016; Jason, 1997). Second, local actors are encouraged to participate voluntarily, as input from the community can help build solid social resilience and environmental resilience in localities. In particular, communities have become the fundamental administrative units for local governance and social mobilization. This is because residents living in the same community will be affected similarly by formal administrative institutions. Local communities are also the most basic unit of social interaction among residents, so the behaviour of residents in the same community will be affected by similar informal systems, historical legacies, norms, local social culture, and kinship networks.

This article is a case study exploring how the Meizhou Community in Yilan County, Taiwan, has successfully developed disaster preparedness over the past ten years, becoming an important role model for more than four hundred communities in Taiwan and praised by international experts and visitors: "The evidence that Meizhou has become a model for other communities in Yilan County is that there have been no deaths in the neighborhood caused by typhoons or heavy rainfall since the establishment of the taskforce and the implementation of its resilience programs in 2011" (Wu Wen-loong, May 9, 2020). At the same time, we will analyse how, in the wake of Meizhou's engagement in Taiwan's New Southbound Policy (NSP), it has become an exemplary model of community disaster preparedness for Asia. This article adopts the social capital analysis to examine how Meizhou has developed and promoted the concept of resilience and how it is achieving the goal of becoming a self-reliant community in disaster preparedness through successful and continuous collective action.

The authors conducted qualitative methods to investigate Meizhou's case study. This article is based on long-term fieldwork conducted by the authors in the Meizhou community between July 2015 and May 2020. There were 40 interviews including with the commander and members of the Meizhou Taskforce for a DisasterResilient Community and its stakeholders. In order to witness the performance of the front-line disaster preparedness and relief, the authors also engaged in participatory observation during the preparatory activities of the taskforce before Typhoon Maria struck Taiwan between 8-12 July 2019 and in the capacity-building workshops organized by the Meizhou Taskforce for a Disaster-Resilient Community on May 9, 2020, and by the Taiwan-Asia Exchange Foundation (TAEF) on November 6, 2018 and December 19, 2019.

\section{Social Capital Matters: Bonding, Bridging and Linking Elements}

Most social scientists recognize that social capital contributes positively to enabling collective actions and sustainable community-building projects (Fulkerson \& Thompson, 2008; Lin, 2002). Some of them, in particular, address its contribution to a community's disaster resilience (Aldrich, 2012; Delhey \& Welzel, 2012; Freitag \& Traunmüller, 2009). Social sciences literature shows that social capital matters, although little has been discovered about how social capital works in detail. In order to unpick how social capital works, this article utilizes Juheon Lee's categorization of three elements of social capital: namely, Bonding Social Capital (BSC), Bridging Social Capital (BrSC), and Linking Social Capital (LSC; Lee, 2020, p. 34; see Table 1) to investigate the Meizhou experience in building disaster resilience.

In terms of BSC, it refers to a close relationship that builds cohesion within homogeneous groups. It is the social proximity associated with a specific locality's unique social/historical background, which includes the interpersonal relationships or special social networks and partnerships (Rubin \& Rubin, 2007). The BSC includes a sense of trust and identification among members of one community. It has two meanings, one is identification with core values and beliefs, and the other is trust in leaders or core groups. The BSC will nourish the social network of a community as a partnership originating from residents' close daily interactions, including relationships between neighbours, kinship or families, collective farming experiences in an agricultural village, or through the everyday life of working in the same factory. These interactions allow community members to become familiar with one another and to develop a high degree of trust (Lee, 2020, p. 34).

Regarding the $\mathrm{BrSC}$, it activates horizontal ties with heterogeneous groups beyond geographical proximity. Despite some weak ties, the $\mathrm{BrSC}$, which aims to create external connectedness, can bring people or groups across diverse social divisions to collaborate in delivering public services or to pursue integration into a wider society (Lee, 2020, p. 34). Sometimes the functions of these groups are complementary and a better exercise of the $\mathrm{BrSC}$ may harmonize conflicts of interests and foster synergetic output through social coordination.

Finally, Lee (2020, p. 34) regards LSC as an enhancement mechanism of the vertical relationship between groups and those with power or higher authority. The LSC can be utilized by the community to seek external resources or social recognition. For example, for those communities lacking resources, enhancing the LSC to link with the authority concerned may gain more tangible support to make their operation sustainable. If the community, being recognized, can also strategize the LSC to highlight its operating model as an important part of some national policy, such as for empowering local economic growth or for solving some developmental prob- 
Table 1. Comparing elements of social capital: Elements and features.

\begin{tabular}{llll}
\hline & Bonding social capital & Bridging social capital & Linking social capital \\
\hline Functions & $\begin{array}{l}\text { Enhancing cohesion within } \\
\text { the community }\end{array}$ & $\begin{array}{l}\text { Activating partnership among } \\
\text { functional groups }\end{array}$ & $\begin{array}{l}\text { Linking vertical tie between } \\
\text { groups and those with power } \\
\text { or authority }\end{array}$ \\
Types of ties & $\begin{array}{l}\text { Individual/ } \\
\text { actor B }\end{array}$ & $\begin{array}{l}\text { Internal } \\
\text { Strength of tie }\end{array}$ & Strong tie (internal cohesion) \\
Purpose & Weak tie (external connectedness) & Vertical tie (external recognition) \\
(bring like-minded people & Functional partnership (make & $\begin{array}{l}\text { Seek for external resources } \\
\text { (make people recognized) }\end{array}$ \\
\hline
\end{tabular}

Source: Authors' own elaboration based on Lee (2020).

lems, a partnership endorsed by a group with power or higher authority to implement effective governance will be facilitated.

\section{Mizhou Experience in Disaster Resilience: A Social Capital Analysis}

\subsection{Profile of the Meizhou Community, Yilan County}

In Taiwan, local communities that are regularly threatened by extreme weather conditions try to build disaster resilience through the voluntary and collective actions of residents and through community-building projects, seeking to prevent disasters or mitigate potential losses. This type of community-empowerment project has developed a more efficient model of disaster governance. According to Taiwan's experience, there are three conditions for realizing a disaster-resilient community: First, the community needs to have the ability to reduce the chance of disasters; second, the community needs to have the ability to withstand the impact of disasters and mitigate losses caused by the disaster; third, it is necessary to practice the rapid post-disaster recovery and reconstruction for sustainable development.

In recent years, due to government support and the rise of a vibrant Taiwanese civil society, this kind of community self-sufficiency through Public-Private Partnerships has made up for the shortcomings of the central government or local government in caring for localities and ensuring the safety of residents when natural disasters occur. Although a community may receive assistance from the government in the form of emergency rescue or reconstruction, a disaster-resilient community can quickly and spontaneously take independent action to restore the social and economic order before the government intervention occurs.

The Meizhou community of six thousand inhabitants is located in the northwestern part of Yilan City cover- ing an area of 500 hectares. Meizhou's low-lying agricultural plantation, on the Yilan River and adjacent to multiple creeks, makes it one of the most vulnerable areas in the county to flooding. Before the river embankment was built 30 years ago, Meizhou was often flooded up to a height of three meters when heavy rains and typhoons struck with many deaths and losses being caused by each typhoon that hit Taiwan. The embankment had been helping to prevent flooding until very recently, but now the weather is growing ever more extreme. The flooding has become so serious that many senior residents have drowned in ditches or flooded paddy fields when they accidentally strayed off the roads. In recent years, furthermore, Meizhou society has aged considerably as the majority of its young people have moved out to neighbouring cities to study or work. In response to these problems, the residents of Meizhou took steps to become self-reliant in disaster preparedness. Ten years on, Meizhou has not only become a model for the more than four hundred communities in Taiwan that have sought to become self-reliant in coping with flooding; it has also gained international recognition.

\subsection{How Social Capital Works: Enhancing Bonding Capital for Community Cohesion}

The Meizhou Community is a traditional rural village, most of whose residents are engaged in agricultural activities. It is rich in the values of sharing and caring typically found in Taiwan's countryside (Huang, 2006; van Zomeren \& Louis, 2017), and interpersonal relationships are strong. Furthermore, since most of Meizhou's residents have lived in the community for decades, they feel closer to each other than residents of modern communities nearby which adds to the accumulation of the community's BSC and effectively bonds the residents together. As early as 2004, a few residents in Meizhou took the initiative to establish a Community Watch Team. 
The team, a voluntary organization headquartered in the community's activity centre, was originally set up to strengthen community security. Due to the poorly lit streets and zigzagging roads, elderly residents frequently get involved in traffic accidents. When accidents occur, members of the Watch Team rush to the scene (Wu Wen-loong, April 4, 2020). In addition to traffic accidents, the team also focuses on caring for the health and safety of elderly people who live alone, for example, making sure that those who need medical treatment are able to get to the hospital. This kind of social network which grew out of the community's daily life helped to promote a sense of social cohesion and solidarity among residents, then leading to trust in the community for disaster preparedness and relief projects.

In addition to the strong ties nourished by BSC, most of the residents in Meizhou have worked on farms and have become accustomed to living at the mercy of the weather. Since the area is vulnerable to drought and floods, residents have expanded their preparedness to include mitigation efforts, such as by setting up warning systems for flooding or other natural disasters. After disasters caused by severe floods or high winds, members of the Watch Team and other residents come together to support the community and clean up afterwards. Watch Team members said that when trees brought down by typhoons obstructed traffic, team members were mobilized to clear the debris before the city officials were able to dispatch personnel to do the work. They also help to drain flooded fields. All of these demonstrate the community's idea of resilience-the community's disaster prevention network taking action to protect fellow residents and provide public services whenever the local government is slow to respond. Mr. Jan, the Deputy Commander of the taskforce mentioned that if an older resident living alone had not been seen near his home in the evening, they would call to ask if he needed assistance. If he could not be reached, taskforce members would hurry to his house to check whether he was alright (Ho-lun Jan, August 19, 2019).

The Watch Team has nourished strong ties among its members. Given that most of its members are relatives, classmates, long-time neighbours, and co-workers, they have accumulated a rich array of social capital, and every Tuesday and Friday they organize work meetings or social events at Wu Wen-loong's house. The driving force to the success of Meizhou also relies on solid leadership (Renshaw, 2018) and cohesion among its core members. After the establishment of the Meizhou Community Development Association in 2004, its chairman, Wu Wen-loong, was appointed leader of the Watch Team. Because the community was prone to flooding, the Meizhou Community Development Association hoped that the responsibilities of the Watch Team could be expanded beyond those of community security to include working towards disaster preparedness. Watch Team members agreed to do more than provide a passive post-disaster response; they wanted to be more proac- tive in prevention and preparedness. Once the residents had realized what they could do in terms of disaster prevention, they began to undertake regular drills so they could mobilize residents when the emergency was at an earlier stage, and thus reduce losses. Commander Wu then told a meeting of the Watch Team about the resilient community idea. Wu mentioned that:

All the team members at that time agreed to expand our operations to include disaster preparedness given the lack of resources and funds. They [agreed] to take the lead in the community and share Meizhou's experience with other like-minded communities in Yilan, which may have made a significant contribution to the development of a resilient Taiwan. (Wu Wen-loong, November 11, 2019)

He also mentioned how he hoped to use the existing mechanisms to mitigate the effects of natural disasters (initially, flooding in the wake of typhoons and heavy rainfalls). Wu had gained the trust of his fellow team members who had seen him lead the team in carrying out disaster relief work after typhoons. He thus became a key leader in the successful process of developing Meizhou and other like-minded communities to become self-reliant communities for disaster preparedness.

The services provided by the Watch Team members are unpaid. In the event of natural disasters, they have helped to solve many problems in the community and gained trust and recognition among community residents. Therefore, they rarely face challenges when they initiate social mobilization, as the residents are willing to cooperate with their arrangements. Meizhou residents, moreover, inspired by Commander Wu Wen-loong and the Watch Team, exhibited strong social cohesion. Initially, the Watch Team had about 40 members, only 20 of whom were extremely active core members. The community's activity centre once again served as its base. In 2011, Typhoon Megi brought severe flooding to the area and most of the fields and roads were underwater, causing serious losses and casualties. After their posttyphoon debriefings, Wu Wen-loong and the core members of the Watch Team decided to transform the team into the Meizhou Disaster Preparedness Taskforce, with its headquarters in the community activity centre. Unlike contemporary community efforts being introduced and initiated by young people, the Meizhou elderlies have resorted to empowering each other to address the recurring environmental challenges they experience.

\subsection{Expanding Network through Bridging Social Capital: Let's Work Together for Our Family}

After brainstorming together with Watch Team members in 2012, Commander Wu decided to invite more stakeholders to engage in community-based disaster resilience efforts, including: 
1. Medical Personnel: Commander Wu invited a physician, Dr Chien-Tsai Huang, and a caregiver from a local clinic in Yilan City to join the taskforce, sharing their medical expertise regarding emergency medication with the Team members, while joining and strengthening the preparedness of relief programs.

2. Primary School: The Taskforce usually practices emergency drills in Shin Sheng primary school in the neighbourhood and invites teachers and neighbouring residents to observe. Moreover, as the Meizhou community is now ageing, community efforts on disaster resilience lack vibrant youth participation; in order to encourage more participation from the younger generation and to share knowledge of disaster preparedness with more families, the taskforce worked closely with Shin Sheng primary school to organize workshops on earthquake drills and disaster preparedness. From 2013 onwards, students actively engaged in practising the preparedness programs and took the lessons learned back home to their grandparents and senior family members. This partnership made more residents aware of the importance of disaster resilience at the local level.

3. Micro, Small, and Medium Enterprises: The work of the Meizhou Taskforce in clearing debris during typhoons and floods helps allow micro, small, and medium enterprises in the community to quickly resume operations following disasters. Some of these companies, such as Huadien, a computer company, donated electronic whiteboards and other computer equipment to the Taskforce in 2018 which made their work of gathering information about impending natural disasters and communicating with government agencies and other stakeholders more convenient.

4. Academic Institutions and University Research Centres: Promoting community-based disaster preparedness is a complex process. Taskforces need regular intellectual input and professional support from experts and scholars. Over time, Meizhou established partnerships with disaster prevention experts at Taiwan's Feng Chia University, National Cheng Kung University, and National Taiwan University. Experts and scholars from these academic institutions and universities provided the Taskforce with disaster prevention technology (i.e., how to use the smart platform that integrates Hydrometeorology and the Disaster Reduction database) and updated professional knowledge (i.e., how the movement of typhoons impacts the flood-prone area of the neighbourhood) which is then passed on to the community's residents. Those scholars and experts also benefited from the front-line experience of practising disaster preparedness and relief shared by the Taskforce. One of the part- ner experts, Professor Tan Yi-chi of disaster management studies, once shared the Meizhou experience in his lecture on an international development program in Belize, Taiwan's diplomatic ally in the South Pacific. In addition to learning disaster prevention technology and professional knowledge, Commander Wu Wen-loong also cooperated with National Chengchi University's Center for Southeast Asian Studies (CSEAS) by working on dialogues with experts and community leaders from Southeast Asian countries. This enabled him to share Meizhou's disaster prevention experience with other disaster-prone Southeast Asian countries and communities from the exchange programs and dialogues, and the Taskforce and residents also learned best practices and innovative operational codes from Southeast Asian and international counterparts and practitioners.

5. Civil Society Organizations: Commander Wu highlighted the importance of working with NGOs to gain greater support from civil society. In 2019, through the network of the Rotary Club of Yilan, some business leaders donated necessary items of emergency equipment and electric chainsaws to the Taskforce, showing their appreciation for the disaster preparedness and relief efforts made by the Taskforce.

With the help of the stakeholders, the taskforce has gradually divided itself into four teams, each with a different function as follows:

1. Patrol and Early Warning Team: Responsible for collecting weather information and government weather warnings, as well as inspecting floodprone areas and ditches in the community (most of them are members of the early Watch Team).

2. Preparation and Rescue Team: In charge of obtaining supplies and rescue equipment to be kept at the community activity centre before typhoons (most of them are members of the early Watch Team).

3. Reporting and Evacuation Team: Collates information collected by the inspection team, warns residents, especially elderly residents living alone, about impending disasters and cautions people to avoid flood-prone areas. In the event of a largescale disaster, such as a typhoon, this team also liaises between residents and the police.

4. Medical Care Team: Takes care of the elderly, especially those living alone, and disadvantaged groups in their homes and provides supplies and necessary medical assistance. It includes an Action Support Team that coordinates the allocation of reserve personnel and team members. A physician and a caregiver are essential to this Professional Medical Team, making it the only taskforce with healthcare professionals among more than four 
hundred community disaster prevention teams in Taiwan.

\subsection{Strengthening the Linking Social Capital: A Living Model for Taiwan and Beyond}

Over two decades, the government of Taiwan has actively encouraged bottom-up efforts in disaster resilience, adopting policies that enable communities to build disaster resilience through community governance and Public-Private Partnerships. For example, since 2004, the Soil and Water Conservation Bureau of the Council of Agriculture has promoted "Self-Reliant Communities Against Landslides" and, since 2010, the Water Resources Agency (WRA), under the Ministry of Economic Affairs, has advocated self-reliant disaster prevention communities against flooding. These interministerial initiatives of the central government aim to enhance the role and input of grassroots communities in front-line disaster preparedness, relief, and post-disaster reconstruction. One interesting initiative is the "self-reliant flood disaster prevention community plan" (Wu Wen-loong, May 9, 2020). To encourage communities to strengthen their capacity to mobilize local resources in preparation for natural disasters, the supported communities would go on to demonstrate outstanding performance in this area since 2014.

The Meizhou Taskforce officially came into operation in 2012, and, in the same year, they joined the WRA Community-Based Flood Risk Management Program network. Since 2010, the WRA, under Taiwan's Ministry of Economic Affairs, has promoted self-reliant community flood prevention under the auspices of the central and local governments. The network has strengthened the ability of local communities to prevent disasters through regular drills, preparations, and emergency response. Commander Wu and other core members of the Taskforce believed that Meizhou already had some capacity to carry out local mobilization. They felt that if it could strengthen its institutional ties with the government and participate in the official disaster governance network, both the Taskforce and the residents would be able to learn more about disaster preparedness from intensive cooperation with other like-minded communities and gain more support from authorities. In 2013, the Meizhou Taskforce took part in flood prevention drills in northern Taiwan for the first time.

Through guidance from central and local government, routine drills, and maintenance, and by responding to actual emergencies, many model communities have been developed which act as examples for other localities. The development of these resilient communities has been beneficial to Taiwan. Over the past five years, Taiwan has experienced 23 typhoons and 22 incidents of torrential rain, during which time the self-reliant flood-prevention communities have taken independent action on nearly 4,500 occasions and have evacuated more than 1,300 people without incurring any casualties.
By strengthening the LSC with the central government agencies, the Taskforce worked closely with the WRA program with the support of its partners from academic institutions and universities. From 2013, it then received the "outstanding community" award for three consecutive years and was nominated as a "model community" for flood and disaster prevention work-Meizhou is one of the most successful models for these resilient communities in Taiwan.

Having had their work recognized by the central government, the local government also paid attention to their high performance. After being nominated as a model community for flood prevention in Taiwan, the Yilan City Office and Mayor Chiang Tsung-Yuan committed to providing them with full support on many occasions. Moreover, representatives from the Meizhou Taskforce were invited to speak at other local governments and communities to share their experience of disaster preparedness, and commander Wu has become an active promoter of the concept of resilient communities. He emphasizes that besides quickly restoring order after a natural disaster, it is even more important for communities to focus on preparation work; these efforts need to start with the community and be implemented by all residents (Wu Wen-loong, April 1, 2020).

The Taskforce aimed to share their experience with their international counterparts by enhancing its LSC as the Taiwan Government began to emphasize its ties with neighbouring Southeast Asian countries in 2016. The team from CSEAS as the partner of the Taskforce helped Meizhou apply for a grant project from the US State Department's Alumni Engagement Innovation Fund (AEIF 2019) which it received in 2019. This was an important step in the internationalization of Taiwan's disaster preparedness experience in the Indo-Pacific region. In the past two years, the Taskforce has also begun to cooperate with the TAEF, which is an important policy think tank promoting Taiwan's NSP to strengthen peopleto-people ties and exchange between Taiwan and its counterparts in Southeast Asian countries. Furthermore, TAEF is regarded as the government's fifth flagship program of Taiwan's NSP, the signature foreign policy of Taiwan's President Tsai Ing-wen. Through TAEF's regional network, Meizhou, being a partner community of TAEF's core action plan, building regional resilience (TAEF, 2020), has been in contact with communities and disaster prevention teams and experts in Japan, Indonesia, Myanmar, Thailand, and the Philippines. Meizhou's efforts have also been introduced in TAEF's exchange program and the NSP's capacity-building projects. One Thai expert of disaster governance who participated in the "Workshop on Disaster Governance and Prevention: Taiwan-Thailand Dialogue" co-organized by the TAEF and the Meizhou Taskforce in Yilan, said, "I found the Meizhou experience of community-based governance of disaster preparedness and on cross-sectoral partnerships to be a valuable reference for thousands of local communities in Thailand" (Saifon Suindramedhi, December 11, 
2019). To work with the TAEF, Commander Wu emphasized, strengthens the implementation of the LSC and advances the gaining of international recognition. Most members of the Taskforce feel proud of being part of a team that works to strengthen Taiwan's international reputation.

In 2019, a report in the Jakarta Post introduced the "Meizhou experience" to the people of Indonesia. Together with CSEAS and TAEF (Syafrizaldi, 2019), Meizhou has continued to enhance its model to become an important part of Taiwan's national policy and promote the internationalization of its experience and the development of an international network of partners. With the input of the Meizhou experience, it demonstrates that Taiwan's NSP is not only concerned with developing economic and trade ties with neighbouring countries, it is also actively responding to the needs of people and communities in Southeast Asia and cooperating to achieve resilient communities. The Meizhou Experience in disaster efforts can be summarized and illustrated in Figure 1 as follows.

\section{Conclusion}

Utilizing a social capital analysis, this article identifies how the Meizhou Community exercises three separate elements of social capital to implement its vision and program of being a disaster-resilient community. Since the Taskforce of disaster resilience was established in 2012, it has gradually transformed itself from a neighbourhood watch team into a well-organized and multi-functional taskforce consisting of four teams delivering a range of public services to the community's residents based on a strong social network. More recently, the Taskforce has adopted a strategy of institutionalization and internationalization, expanding its influence in Taiwan and throughout the Indo-Pacific region.

We argue that the case of the Meizhou Taskforce is worth noting in Taiwan. It not only has solid BSC within the residents of the Meizhou community but also extends the $\mathrm{BrSC}$ to invite stakeholders of diverse social divisions to work together. During our fieldwork, the commander and taskforce members collectively demon-

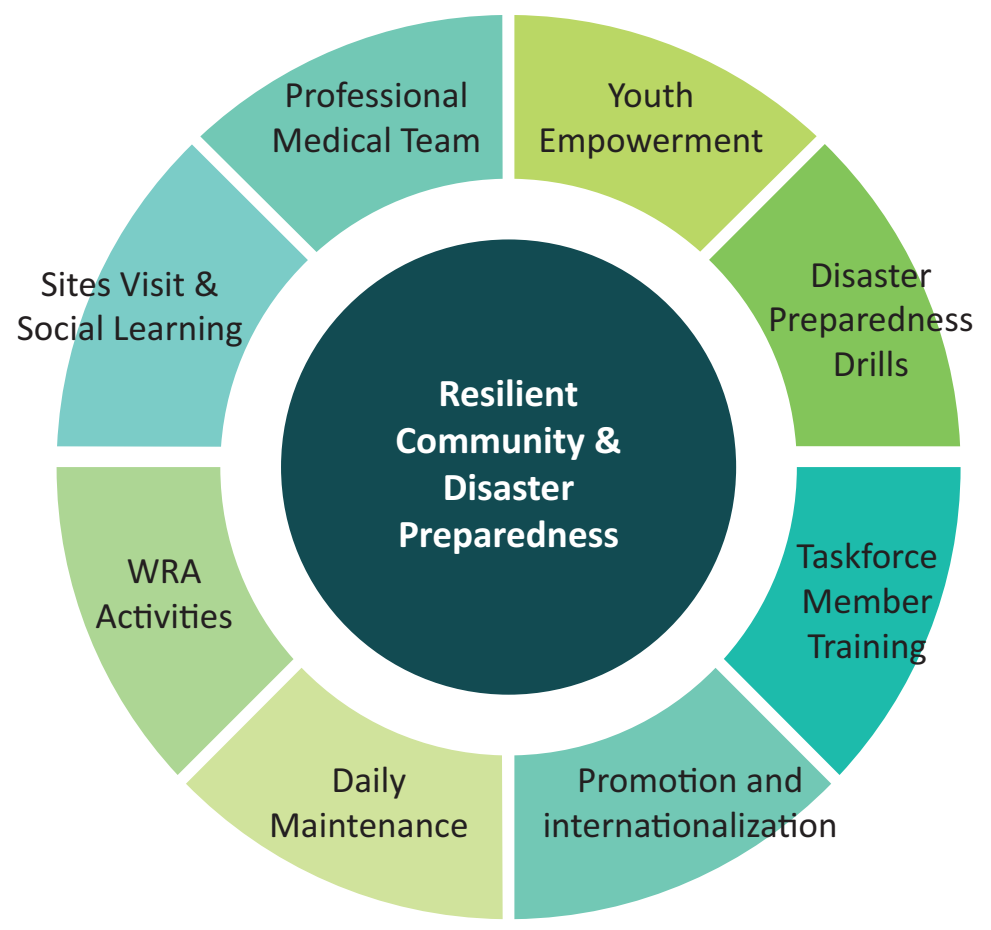

Figure 1. Operation of the Meizhou Taskforce for disaster preparedness. Notes: Daily maintenance includes maintaining the Jintongchun irrigation canal and drainage ditches every day; Taskforce members training includes regular training programs and workshops for taskforce members; Professional medical team includes continuing partnerships with medical doctors and caregivers in providing emergency medical assistance or deliver medication during disasters; Youth empowerment: enlightening projects to raise public awareness in primary or secondary schools in the neighbourhood; WRA activities includes taskforce members attending and sharing in WRA organized workshops and seminars on disaster preparedness and emergency governance; Disaster Preparedness Drills include local exercises and regional drills in partnership with public sectors and other community taskforces; Site visits and social learning: taskforce members regularly visit other likeminded communities in remote areas and taskforces to share and learn insights and know-how with other taskforces; Promotion and Internationalization: efforts facilitated by the AEIF 2018 project and by the NSP, the taskforce continues to promote and participate in international exchanges, focusing on communications of disaster preparedness and experience on restoring social resilience with Southeast Asian countries and community leaders. 
strated solid commitments to serve the common good of the neighbourhood. More importantly, the leadership and the Taskforce strategize their efforts by strengthening its LSC so as to highlight the Meizhou experience as an effective model of community-based governance for disaster preparedness. This fits well with the promotion of Taiwan's signature foreign policy as well as being an example of Taiwan sharing its soft power resources with the countries of Southeast Asia and the Indo-Pacific. Meizhou, like Taiwan as a whole, has learned to be resilient and found ways of overcoming its many challenges through partnerships.

We also found that the experience of Meizhou is enlightening among Taiwan's localities due to its holistic approach to disaster management. Whereas community participation in disaster risk-reduction management is now widespread, the Meizhou Taskforce for a DisasterResilient Community has always been autonomous and has remained citizen-led, even from its early Community Watch Team days. The Taskforce's organizational structure and composition are also worth noting as, contrary to contemporary community efforts being initiated by young people, the older residents of Meizhou have empowered each other to address the recurring environmental challenges experienced by their community. This conscious capacity-building effort, being innately developed-as opposed to being influenced by external actors (e.g., government agencies)-despite the members' more advanced age, is unprecedented and has become a model for best practice throughout Taiwan.

The Meizhou experience highlights some valuable lessons that can be learned by like-minded disasterresilient communities in Taiwan and beyond, in terms of structural organization and routine operation. One of the lessons is that it is imperative to cultivate strong leadership and build up an efficient taskforce to provide public services despite the absence of government operations. The accumulation and operation of BSC and BrSC become key to this process.

Furthermore, in terms of resources and social recognition, the Meizhou experience is also encouraging. An important message that can be shared with other disaster-resilient communities is that most communities in Taiwan are striving for government resources as a single source of support. Despite highlighting distinguished features, it would be very competitive for hundreds of communities to seek limited resources and sponsorship from the public sector. Contrary to this, Meizhou's strategy is to seek support to strengthen its LSC and to promote the internationalization of their efforts in practising disaster preparedness and resilience; that is, to reinforce its $\mathrm{BrSC}$ and LSC strategically. As they are recognized internationally, the government and other public sectors in Taiwan will show great interest in working with them. Furthermore, it would be easier to strive for meaningful partnerships and substantive support with the public sector while shaping their uniqueness.
Although the Meizhou experience emphasizes a resilient model of leadership, sustainable organization, and multi-functional partnerships in terms of practising Bonding, Bridging, and Linking Social Capital, as time goes by and the Meizhou community ages, the Taskforce must attract more youth participation to enable their efforts of disaster preparedness. It would also be a key lesson for Meizhou and other like-minded communities in Taiwan to consider long-term sustainably and include younger members.

\section{Acknowledgments}

The authors would like to acknowledge the assistance from the Meizhou Taskforce for a Disaster-Resilient Community for the interviews and participatory observation conducted by the authors. Special thanks go to the Taiwan-Asia Exchange Foundation (TAEF) for organizing workshops and to the American Institute in Taiwan (AIT) and the United States Department of State for facilitating the Alumni Engagement Innovation Fund (AEIF) projects with the Meizhou Community taskforce between 2018 and 2020.

\section{Conflict of Interests}

The authors declare no conflict of interests.

\section{References}

Aldrich, D. P. (2012). Building resilience: Social capital in post-disaster recovery. Chicago, IL: University of Chicago Press.

Chen, Y. Y., \& Ku, Y. W. (2016). Community practice at a crossroad: The approaches and challenges in Taiwan. Community Development Journal, 52(1), 76-91.

Fulkerson, G., \& Thompson, G. (2008). The evolution of a contested concept: A meta-analysis of social capital definitions and trends (1988-2006). Sociological Inquiry, 78(4), 536-557.

Freitag, M., \& Traunmüller, R. (2009). Spheres of trust: An empirical analysis of the foundations of particularised and generalised trust. European Journal of Political Research, 48(6), 782-803.

Huang, J. (2006). Taiwan in transformation 1895-2005: The challenge of a new democracy to an old civilization. New York, NY: Transaction Publishers.

Jason, L. (1997). Community building: Values for a sustainable future. Westport, CT: Praeger.

Lee, J. (2020). Bonding and bridging social capital and their associations with self-evaluated community resilience: A comparative study of East Asia. Journal of Community \& Applied Social Psychology, 30(1), 31-44.

Lin, N. (2002). Social capital: A theory of social structure and action. Cambridge: Cambridge University Press.

Renshaw, D. (2018). Concerns of the communal leaderships. In Socialism and the diasporic 'other': A com- 
parative study of Irish Catholic and Jewish radical and communal politics in East London, 1889-1912 (pp. 137-180). Liverpool: Liverpool University Press.

Rubin, H. J., \& Rubin, I. S. (2007). Community organization and development (4th ed.). Columbus, $\mathrm{OH}$ : Merrill Publishing.

Syafrizaldi. (2019, March 5). Coping with disasters, Yilan style. Jakarta Post. Retrieved from https://www. thejakartapost.com/life/2019/03/04/coping-withdisasters-yilan-style.html

TAEF. (2020). TAEF program on regional resilience. TAEF. Retrieved from https://www.taef.org/44

van Zomeren, M., \& Louis, W. R. (2017). Culture meets collective action: Exciting synergies and some lessons to learn for the future. Group Processes and Intergroup Relations, 20(3), 277-284.

\section{About the Authors}

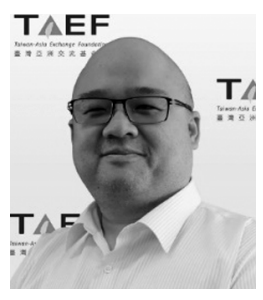

Alan Hao Yang (PhD) is Professor of Southeast Asian Studies at the Graduate Institute of East Asian Studies and Deputy Director of the Institute of International Relations (IIR) at the National Chengchi University (NCCU), Taiwan. He has been engaging in think tank diplomacy and currently works as the Executive Director for the Taiwan-Asian Exchange Foundation (TAEF). He was one of the awardees of the Alumni Engagement and Innovation Fund (AEIF 2018) on building a resilient community in Asia sponsored by the State Department of the United States in 2018. His research interests cover international relations theories, comparative regionalism, environmental governance and disaster resilience, border politics and politics of resistance in southeast Asia, foreign policy and soft power analysis, and Taiwan's New Southbound Policy.

Judy Shu-Hsien Wu is a Doctoral Student at the Graduate Institute of East Asian Studies at the National Chengchi University (NCCU), Taiwan and an Assistant Research Fellow at the First Research Division at the Chung-Hua Institution for Economic Research (CIER). Her research focuses on how China uses economic statecraft or economic diplomacy in pursuit of geopolitical Influence. She also examines the effectiveness of economic statecrafts with BRI railway projects in Vietnam, Laos, Cambodia, and Myanmar. Her research interests cover international political economy, comparative authoritarianism, area studies, especially in China and Southeast Asia. 